\title{
O Produtivismo e suas Anomalias
}

\author{
Productivism and its Anomalies
}

Christiane Kleinübing Godoi ${ }^{1}$

Wlamir Gonçalves Xavier²

Em 2011, a Divisão de ensino e Pesquisa em Administração e Contabilidade da ANPAD completou dez anos de existência e de consolidação do seu papel como promotora de discussões transversais, de caráter pedagógico, metodológico e institucional, da área de Administração como um todo. A criação no interior da Divisão de outro tema destinado a questões institucionais - Estudos Históricos, Reflexivos ou Críticos sobre as áreas de Administração e Contabilidade - foi um dos principais fatores que impulsionaram a Divisão a promover o III EnEPQ como espaço indutor do debate e de reflexões críticas de problemas específicos considerados relevantes para a área. O momento não poderia ser mais propício à reflexão sobre o que significa ensinar e pesquisar no Brasil e sobre o que se poderia chamar de trabalhos de qualidade. A escolha de um tema de interesse da comunidade e de três brilhantes professorespesquisadores ocorreu nesse cenário de planejamento do encontro de uma Divisão que, em virtude de sua essência, não pode eximir-se de participar da reflexão, da promoção da informação reflexiva e da disponibilidade em mudar.

A partir das reações provocadas pelos textos dos painelistas - Maria Ester de Freitas, Alexandre Faria e Rafael Alcadipani, publicados na Seção Opinião desta publicação (v. 9, n.4) iniciamos, a seguir, a discussão de alguns pressupostos que assumimos como ponto de partida para a busca do foco e do argumento central deste ensaio.

\section{Qual Produtivismo? Saudades de 2008}

Definições, algumas por vezes irônicas, e diferentes compreensões críticas do que seja este fenômeno cultural, de origem econômica, ideológica e filosófica, chamado produtivismo acadêmico, já foram amplamente tratadas na literatura brasileira, principalmente no campo de educação (SGUISSARDI, 2010a; 2010b; BIANCHETTI e SGUISSARDI, 2009; BIANCHETTI e MACHADO, 2009). A própria definição é dialética, pois já engendra em si a crítica: forma de avaliação centrada na quantidade pura e simples de produções/publicações, em geral pouco lidas ou que não têm maior importância científica, e que serve de parâmetro básico para as mais diversas formas de progressão na carreira acadêmica. A maior parte da crítica é direcionada ao fato de que o centro desse modelo reside em considerar o quanto docentes/pesquisadores/programas/instituições publicam em detrimento da qualidade científica ou da relevância social do que é publicado.

Na pós-graduação brasileira em gestão - âmbito deste ensaio - o produtivismo acadêmico adquire força de sobrevivência e perpetuação pelos diversos dispositivos de incentivo ao desejo de competição entre: universidades, programas de pós-graduação, docentes-pesquisadores e, até mesmo, entre discentes (SGUISSARDI e SILVA JÚNIOR, 2009; BIANCHETTI e MACHADO, 2009). Ainda que a chegada oficial do produtivismo acadêmico no Brasil remeta ao final dos anos 1970 - época em que suas características e

\footnotetext{
${ }^{1}$ Professora do Programa de Pós-graduação em Administração - PPGA/UNIVALI; Doutora em Engenharia de Produção - UFSC. Endereço: Av. Mauro Ramos, 1323, apt. 902, Centro, CEP 88020-302 - Florianópolis-SC. E-mail: chriskg@univali.br

2 Professor do Programa de Pós-graduação em Administração PPGA/UNISUL; Pós-doutorado (em andamento) FGV-EAESP. Endereço: Rua Duarte Schutel, 61 apt. 101, Centro, CEP 88015-640 - Florianopolis-SC. E-mail: wlamir.xavier@unisul.br
} 
efeitos passaram a ser visíveis (SGUISSARDI, 2010b) - e, de forma legitimada, aos anos 1990, a ênfase na quantidade em detrimento da qualidade como critério de avaliação de professores-pesquisadores e programas torna-se, a cada ano, mais evidente entre nós, por meio de suas sequelas.

No campo da administração, os primeiros textos capazes de promover alguma polêmica e ampla discussão na área foram publicados em 2008 (MATTOS, 2008; ROSA, 2008). A releitura atual destes textos permite identificar o agravamento considerável dos efeitos desse fenômeno social construído por nós e capaz de alterar a realidade na qual somos impelidos a viver. O retrato descrito, em 2008, era de um quadro ainda razoável, denominado apenas de "pressão por publicação" - uma tolerável e pré-produtivista pressão psicológica diante da imposição de uma meta considerada viável para a época: 12 pontos por ano. Nessa época já se falava em "síndrome de stress acadêmico", porém a patologia não era epidêmica e, se alguém desejasse, poderia localizá-la na falta de organização ou marasmo de indivíduos isolados. Ainda que possamos discordar de que essa mínima exigência fosse viável a todos os professores, não é este o foco que se pretende imprimir aqui, pois a meta aparente não parece ter sido substancialmente alterada durante o período, ou seja, os 12 pontos anuais mantêm correspondência os 50 pontos/ano atuais. Nesta constatação, reside o estranhamento e o problema que pretendemos compreender: como a nociva máquina produtivista evoluiu a ponto de gerar as mais diversas anomalias e, em que momento, passamos a fazer parte dessa engrenagem fechada cujo termo "produtivismo" já foi assimilado por todos e, como tal, perdeu seu significado original. Trata-se hoje precisamente de uma fábrica de fazer pontos - isso é o imaginário no qual acreditamos e, por vezes, até admiramos. Em última instância e, com todos os sintomas, o produtivismo transformou a academia em uma perfeita "fábrica de loucos", sem vítimas ou algozes.

Podemos entender a lógica nefasta dessa máquina, inicialmente de forma simples: há uma regra imposta por quem possui os recursos financeiros de que a universidade não pode prescindir. Depois há que considerarmos: até que ponto há elementos exógenos nesse processo? A comunidade acadêmica é mera vítima ou coautora de fato e de direito dessa situação? Escolher um culpado externo ao sistema é cômodo e confortante, o papel de vítima sempre cai bem. Também é comum ouvirmos nos corredores das universidades reclamações sobre a imposição de carga excessiva de trabalho, a redução da autonomia das instituições e o fim da liberdade dos pesquisadores. A lógica excludente da culpabilidade até o momento apenas contribuiu para a nossa acomodação e, até mesmo, as queixas, cada vez menos verbalizadas, já fazem parte de uma realidade tomada como inevitável.

\section{Anomalias do produtivismo: a constituição do ciclo insano}

Ao eleger o foco deste ensaio, consideramos priorizar aspectos tangenciados ou que escaparam à abordagem dos painelistas que iniciaram esse debate (FREITAS, 2011; FARIA, 2011; ALCADIPANI, 2011), em vez de enfatizar as facetas do fenômeno por eles aprofundadas. Trataremos, portanto, de um olhar particular sobre o sistema produtivista acadêmico suscitado pelos que nos antecederam, mas sobre o qual assumimos a responsabilidade de falar a fim de ampliar o debate a partir daqui mobilizado. Cabe ressaltar que se trata de tema que mobiliza nosso interesse e diálogo, desde 2008, quando tivemos a oportunidade de estudar o problema sob a ótica de dominação em Foucault (XAVIER e GODOI, 2010).

Não se pretende neste espaço retomar as origens econômicas do produtivismo, narradas nos estudos de Sguissardi referenciados neste texto, nem tampouco ousar discutir a brilhante retrospectiva histórica e geopolítica que pode ser encontrada no texto de Faria (2011). Também não resta dúvida de que a reforma na educação vivenciada no Brasil, na última década, modificou a identidade da universidade e dos professores, que tiveram todas as esferas de suas vidas invadidas. São os diversos tipos de anomalias que presentificamos em nosso cotidiano e, com os quais, por vezes nos identificamos, que pretendemos discutir. Cinco dimensões foram tomadas como objeto nos capítulos a seguir. Enfatizaremos, ao final, as duas esferas mais prejudicadas como consequências dessa perda identitária, que estamos denominando anomalias, não no sentido elogioso do termo, como distanciamento da normalidade, mas como deformações e, por vezes, aberrações. 


\section{Papers anômalos: produção científica ou empilhamento?}

Iniciamos a análise do ciclo anômalo que mantém o fenômeno produtivista pela caracterização de sua dimensão mais importante, que deveria ser o principal produto acadêmico entregue à sociedade: o conhecimento científico. A ênfase na quantidade de trabalhos acadêmicos tem contribuído para a geração de pesquisas superficiais acerca de assuntos consolidados com limitada relevância e capacidade pífia de criação de conhecimento, conforme discutido pelos painelistas. Para compreender o processo de produção de commodities acadêmicas, recorremos à noção de "empilhamento" desenvolvida por Latour (1994; 2000).

Ensinamos aos nossos alunos que o pesquisador não pode prescindir de demonstrar em seu estudo um elenco considerável de referências ilustres no desenvolvimento de seus "argumentos de autoridade" (PERELMAN, 1993; LATOUR, 2000; DEMO, 2011), sob o risco de sua pesquisa ser considerada inválida. A quantidade e o prestígio das referências demonstram, na narrativa crítica de Latour (2000), a força que um enunciado passa a ter na comunidade científica, porém, como sabemos, o autor não pode deixar de organizá-las, de forma coerente, dentro de sua argumentação. Essa amarração é realizada por meio de verdadeiras táticas de guerra, denominadas pelo sociólogo francês de empilhamento, encenação, enquadramento e captação. Neste espaço nos restringiremos à metáfora do empilhamento para entender por que perpetuamos essa forma de produção.

Como parte da estratégia de legitimação do conhecimento, a tática de empilhamento consiste em produção de um texto por meio da junção e entrelaçamento de fotos, figuras, números, nomes e argumentos. No processo de empilhamento, o autor deverá criar camadas sobre sua argumentação, perfeitamente justapostas e amarradas, com o propósito de impressionar o adversário e criar barreiras contra as possíveis controvérsias, impedindo que os opositores de suas afirmações cheguem facilmente ao objeto de pesquisa (LATOUR, 2000). Por meio do empilhamento, o autor tenta convencer a comunidade científica e a sociedade acerca da validade de seus enunciados e participa da disputa pelo status de fato e de verdade. A capacidade de despertar controvérsias constitui, por outro lado, um privilégio que atribui visibilidade ao autor e a seus opositores, uma vez que exige dos demais um posicionamento. Latour (2000) entende uma controvérsia, como a contestação de sentenças que buscam a atribuição de certeza, é capaz de mobilizar atores sociais, arregimentar recursos e, assim, possibilita ao autor participar da construção de fatos sociais. À medida que uma controvérsia torna-se acalorada, seus autores, para protegerem-se de opositores, tendem a fazer alusão ao que outras pessoas escreveram ou disseram, recorrendo ao que Latour (2000) denomina de aliados. A invocação de aliados fortes e cada vez mais numerosos, por sua vez, é o que constitui o "argumento de autoridade", o qual, dentro de uma lógica anômala, tem assumido importância maior do que a "autoridade do argumento" (DEMO, 2011) e reduzido a capacidade de construção argumentativa esperada de um pesquisador a simples utilização de referências prestigiadas, de preferência no mundo anglo-saxão.

O processo de empilhamento demonstra a força do autor e sua capacidade em montar uma argumentação, reunindo aliados e protegendo-se da crítica. Na narrativa de Latour (2000), ao empilhar camadas e referências, o autor induz o leitor a seguir a mesma linha de raciocínio no qual o texto se baseou e a percorrer o mesmo caminho. Nisso reside a força e a fraqueza do empilhamento, alerta Latour (2000), pois permite que o leitor saiba por onde começar a puxar se quiser soltar o fio da meada do texto. É por este motivo que cada camada deve ser cuidadosamente empilhada sobre a anterior para evitar vãos que deixariam o autor vulnerável. Por certo a análise de Latour sobre a construção da ciência é muito mais complexa, e aqui utilizamos a noção de empilhamento apenas como metáfora de um processo cujo resultado passamos a analisar agora.

A proliferação de papers científicos sob a lógica do empilhamento, não da criação do conhecimento e da relevância social, transformou a publicação desse subproduto em um fim em si mesmo. A ênfase, nos últimos dez anos, foi deslocada da pesquisa e produção de conhecimento para a produção e publicação de artigos. Chamamos ao resultado desse deslocamento de Parnasianismo Acadêmico. A exemplo do seu homônimo literário, o foco reside na forma, o esteticismo impera. Os trabalhos que seguem o movimento do Parnasianismo Acadêmico caracterizam-se por objetivar a publicação pela publicação e, para tanto, trilham o 
caminho mais seguro. Isso envolve tratar de temas consagrados, sempre ancorados na mainstream vigente e, preferencialmente, de forma objetiva. A replicação superficial do conhecimento é o caminho comum, em que novas proposições são evitadas, e nada é contestado, tampouco criado. $\mathrm{O}$ formato é preciso, métricas são observadas como em um soneto, e um roteiro é trilhado cumprindo todas as recomendações estéticas do periódico.

O Parnasianismo Acadêmico ilustra o distanciamento da relevância científica em busca do esteticismo e temas assépticos, universais, tão óbvios que não são passíveis de crítica (o que facilita a publicação). Em outras palavras, são conteúdos tradicionais que nada agregam, mas atendem à necessidade de rápida e efetiva produção. Trabalhos dessa corrente populam as publicações de hoje, em que incrementos ao conhecimento, quando existem, são laterais ou periféricos. O caráter efêmero desses junk papers é evidente. Como nada agregam, são naturalmente descartados e esquecidos, inclusive pelos seus próprios autores. Dessa maneira, a raridade da autocitação não é sinal de modéstia, mas talvez de autocrítica.

Além da supervalorização da forma, outro produto do Produtivismo, evidenciado em trabalhos empíricos quantitativos, é a busca (a qualquer preço) pelos asteriscos. Em estudos quantitativos, como sabemos, quando os resultados do modelo são significativos, os coeficientes são grifados com asteriscos. A significância a $1 \%$, por exemplo, indica que a probabilidade de obter tais resultados aleatoriamente é inferior a $1 \%$, portanto os resultados são confiáveis. $\mathrm{O}$ asterisco nos relatórios, que representa a significância estatística, passou a ser condição sine qua non para publicação. Essa é a garantia de que a pesquisa chegou a um resultado confiável e que as hipóteses foram testadas com uma base de dados adequada. Bettis (2012), no entanto, descreve a deliberada disseminação do falso positivo: o problema de relatar em trabalhos científicos significância estatística quando ela não existe. Essa anomalia é fundamentalmente alimentada pela falta de ética do pesquisador, mas dois vieses colaboram para a sua prática. O primeiro é a pouca relevância dada a estudos não conclusivos (sem os asteriscos), pois a práxis acadêmica sugere que, se os dados não são conclusivos, é porque o estudo ainda não está "no ponto" para ser publicado. O segundo viés considera pouco publicáveis estudos que replicam trabalhos anteriores com o intuito de confirmar o rigor e precisão dos dados e do método, e ampliam o conhecimento sobre o tema por meio da sua validação. Ao contrário de replicações superficiais que apenas reiteram o que já foi estudado, tais estudos por vezes refutam achados e conclusões anteriormente publicadas, identificam erros e desvios e ajudam a precisar a nova fronteira do conhecimento. Raramente são aceitos, em periódicos conceituados, estudos cujos resultados não apresentam significância ou que se limitam a replicar estudos anteriores, independente da sua contribuição teórica ou empírica. Diante de resultados não significativos, a alternativa para o pesquisador conseguir a almejada publicação é a "tortura dos dados". A busca pelos asteriscos pode envolver a manipulação de dados, manipulação de métodos estatísticos, ou a manipulação ex post dos modelos. Essa anomalia, quando não identificada pelos avaliadores do periódico, dificilmente é percebida pelos leitores.

Trabalhos que utilizam métodos qualitativos não ficam de fora das anomalias. Sabemos o quanto pesquisa qualitativa tem sido amadora (DEMO, 2011) em sua proposta de fazer frente ao modelo tradicional. O subproduto anômalo na versão qualitativa de papers é o uso de diversas formas de pseudoanálise do material empírico. Em texto anterior, um dos autores deste ensaio referiu-se a seis formas, já identificadas na literatura, de pseudoanálise discursivas: a) por meio de síntese, caracterizada pelo resumo de trechos da transcrição de entrevistas, ignorando os detalhes e sutilezas discursivas dos dados originais; b) tomada de posição, na qual o pesquisador assume uma postura de aprovação ou rejeição sobre a postura de quem fornece o discurso; c) excesso ou isolamento de citações, revelada pela ausência de comentários do analista acerca dos dados ou, inversamente, pela tendência da redação referir-se às citações ao invés de analisá-las; d) análise circular dos discursos e dos construtos mentais, aquela que acredita que as citações e discursos falam por si e são suficientes; e) falsa generalização, que extrapola os dados propriamente ditos, por exemplo, ao transformar uma determinada característica de alguns participantes em um atributo pertencente a todos os membros da categoria estudada; e f) localização dos elementos, atenta exclusivamente à busca de afirmações no estudo, esquecendo-se de objetivar o exame de como os dispositivos discursivos são estabelecidos (GODÓI e COELHO, 2011). 
Não se pretende aqui adentrar na discussão epistemológica acerca de formas de fazer pesquisa e produzir conhecimento, pois estamos nos concentrando na identificação de uma tipologia anômala de papers que vêm se proliferando no estágio atual do produtivismo em que nos encontramos. Para completar essa análise, cabe mencionar duas importantes deformações éticas na elaboração de resultados de pesquisa. A primeira referese à multiplicação dos textos oriundos de uma única investigação. Não é incomum encontrar diversos artigos emergentes de uma única base de dados construída pelo autor. A tática reside em fragmentar a pesquisa no número máximo de papers, cuja base teórica dificilmente ultrapassa o revisionismo e a tática de empilhar citações, com a finalidade de aumentar a produção. A segunda deformação de caráter essencialmente ético são os diferentes tipos de plágio - fenômeno que vem ganhando tanto espaço no debate acadêmico que passou a constituir um tema de investigação. O estudo de Honig e Bedig (2012) traz uma ampla revisão da literatura sobre plágio acadêmico nas últimas décadas e o resultado da pesquisa realizada pelos autores com os papers publicados na conferência de 2009 do Academy of Management. Dos duzentos e setenta e nove trabalhos pertencentes à divisão analisada, 25\% apresentou alguma quantidade de plágio, e 13\% da amostra revelou conter plágio significativo. Ainda que tenhamos apenas a suspeita de que os resultados deste estudo sejam transferíveis à realidade brasileira, o que pretendemos aqui é assinalar a nossa percepção de que um aumento nesses índices vem sendo incentivado pela pressão por publicação. A generalização do plágio não parece ser mais uma questão restrita à personalidade desviante de poucos autores, mas uma patologia acadêmica de origem social que merece investigação séria e profunda, desprovida de moralismo acusatório.

Os diferentes tipos de papers anômalos aqui descritos e metaforizados, induzidos pelo produtivismo, podem ser reunidos em uma categoria mais ampla chamada por Duarte Jr. (2010) de rotten papers - papéis podres, semelhantes aos causadores da recente crise financeira mundial. Esse tipo de trabalho serve a um tipo também emergente de leitor: o que referencia e não lê, capacitado a lidar com planilhas dinâmicas contendo centenas de referências a fazer bibliometrias banais e a estabelecer redes de autores. $\mathrm{O}$ leitor, criado dentro do sistema produtivista, tem pouco tempo para pensar, ler com profundidade e ser crítico. Os trabalhos de qualidade - que por certo sobrevivem - voltariam a ter mais destaque e valor em meio aos rotten papers se fossem avaliados não como produção, mas - e aqui concordamos com Faria (2011) - pela criatividade, capacidade de desafiar os paradigmas estabelecidos e gerar impacto social.

\section{Autorias e coautorias anômalas: a noção de sujeito perverso}

Uma das principais anomalias que estão na base da produção de rotten papers é a perda da noção de autoria e coautoria. Ainda que não haja critérios claros que definam a coautoria, há algum tempo não precisávamos mais do que bom senso para identificar coautorias de fato. A partir do momento em que a lógica do sistema passa a valorizar unicamente a quantidade produzida, formas de maximização começam a ser desenvolvidas. $\mathrm{E}$, diante da obsessão pela multiplicação dos pontos, as mais diferentes formas de abuso dessa prerrogativa estão sendo identificadas. Algumas foram mencionadas por Freitas (2011): conluios para publicação, inclusão de autores que sequer leram o trabalho visando à futura reciprocidade, apropriação de ideias de colegas e alunos, e a costumaz inclusão do nome do orientador em qualquer trabalho desenvolvido pelo aluno.

Os tipos anômalos de coautores são por nós chamados, em analogia com o conceito originário da economia, de free riders. Como pseudoautor, coautor de amigos e dos orientandos, o free rider é autor que não escreve, não colabora, simplesmente usa de sua posição privilegiada para receber os pontos da publicação e benefícios decorrentes. Os eventos científicos são momentos e lugares singulares de demonstração e observação desta distorção. Nos campos da economia, psicologia e ciência política, o free rider, também chamado freeloader (parasita, aproveitador), é um agente econômico que usufrui de um determinado benefício proveniente de um bem, sem que tenha contribuído para a sua obtenção. Logo o problema reside em como controlar, ou limitar, o parasitismo e seus efeitos negativos. A analogia nos parece perfeita. 
Outro personagem anômalo, estilo free rider, é o "burocrata sem consistência", que usa seu poder como gestor para apropriar-se do trabalho do subalterno, gerar seus pontos e ficar "bem na foto" (ALCADIPANI, 2011). Essa combinação entre cargo burocrático e elevada pontuação amplia a concentração de poder e garante a perpetuação do sistema. Tal anomalia possibilita que professores tenham elevada produção, mesmo ocupando cargos administrativos que os afastam quase por completo da docência e das atividades de pesquisa. Detentores dos recursos financeiros para a execução da pesquisa, assim como líderes do projeto, donos de base dados, etc., constituem também personagens que caracterizam a interminável tipologia de free riders ou pseudoautores.

Se analisarmos a anomalia da falsa coautoria sob a ótica da transação, o free rider tem muito a oferecer ao efetivo autor, que perde muito pouco ao incluí-lo na obra. De fato, acrescer um coautor por amizade, como forma de homenagem, ou por coerção social, passa a ser uma prática tolerada e culturalmente aceita na comunidade acadêmica, ainda que de forma velada. A próxima etapa será o abandono do escambo e a precificação da coautoria - um mercado que pode fazer uso dos mesmos instrumentos do execrado comércio de teses e dissertações.

A perda da noção de coautoria é apenas mais um produto nessa prateleira em que a ética está em falta. No dizer de Freitas (2011), a perversão do sistema tornou-se previsível e sequer representa uma novidade. O que talvez nos falte entender é o porquê da nossa resignação e falta de atitude diante da distorção. Enquanto o conceito de autoria não for redefinido e internalizado, continuaremos a observar diversos abusos e a tranquila vida dos free riders. Tranquila porque o "sujeito perverso" - típico da época em que vivemos - não é mais aquele caracterizado pela teoria psicanalítica como "sujeito neurótico", envolvido com uma culpabilidade compulsiva, mas sim o que padece do sentimento de onipotência quando é bem-sucedido e de impotência quando não o é. A vergonha (diante de si) substitui a culpabilidade (com relação aos outros), segundo Dufour (2005).

\section{O sujeito coletivo: o papel dos PPGAs}

Ao refletir sobre as distorções coletivas desse modelo, podemos afirmar, inicialmente, com base nas pesquisas empíricas de Sguissardi e Silva Jr. (2009), que o produtivismo acadêmico está profundamente relacionado com a intensificação e a precarização do trabalho dos professores-pesquisadores no âmbito da pós-graduação brasileira - locus em que é novidade, ou ao menos um fenômeno recente. Os autores encontraram que professores das instituições estudadas, em virtude de vivenciarem condições de trabalho cada vez mais precárias, optam por priorizar as atividades de pesquisa, relegando a um segundo plano o ensino e a extensão. Tornam-se aqui evidentes as consequências dessa inversão de identidade institucional que reinventou uma nova forma de separar pesquisa e docência - para a formação, para o professor e para a própria ciência.

A reflexão sobre o produtivismo no plano de coletividade não pode deixar de incluir no ciclo de anomalias o sistema de competição entre instituições de ensino superior, que se estende aos programas, aos docentes e aos discentes. A competição deixa de ser saudável, porque a partir do momento em que instituições e programas contratam, remuneram, promovem, bonificam e descartam profissionais prioritariamente, em função da sua contribuição ao desempenho do programa, e ignoram outros tipos de contribuição, surgem os efeitos patológicos. Por exemplo, instituições que optam pelo atalho do aumento da sua pontuação pela troca de profissionais pouco produtivos por bons pontuadores. Contratar professores produtivos e usar a chancela de qualidade conferida pelos órgãos regulamentadores abrevia o tempo de capacitar docentes, adquirir experiência e reputação. Esse expediente é útil na avaliação periódica do curso e fundamental no reconhecimento de cursos novos. Cria-se, portanto, a partir daí um novo tipo de professor, o pontuador, aquele cuja única atribuição é produzir artigos ou "fabricar" pontos. Um professor que não está presente na vida do campus, não troca experiências com os pares, não ensina, nem compartilha conhecimento. Ironicamente, o pontuador é frequentemente descartado após a obtenção do reconhecimento, já que, uma vez 
cumprido seu papel, torna-se muito oneroso e alvo de descontentamento entre os demais docentes. Além disso a competição interinstitucional pelos mais profícuos pontuadores gera mais um tipo de interessado no produtivismo: os profissionais que se destacam como produtores de artigos. Salários e bonificações aumentam, ofertas de emprego assomam, e o reconhecimento profissional evidencia-se.

Aos pesquisadores que, com seriedade, dedicação e competência, desenvolvem trabalhos científicos dentro da lógica temporal de maturação necessária à pesquisa reflexiva e, efetivamente, produzem conhecimento, as recompensas pelo esforço de anos são: sacrifício do ensino, da extensão e de si mesmo, para não ser sacrificado pela baixa pontuação; perda do emprego quando ancião, já que o jubileu é a cada 3 anos e, como o seu passado não interessa, o ostracismo vem a galope. O produtivismo, nesta dimensão institucional, atua como "máquina de gastar gente", para emprestar o dizer de Darcy Ribeiro e, de forma perversa, produz uma total distorção nas atividades acadêmicas. Terminamos aqui, compartilhando espanto de Walters (2006): como foi que chegamos a departamentos cheios de acadêmicos infantilizados?

\section{O papel dos eventos e periódicos no modelo produtivista}

A experiência vivenciada por um dos autores deste ensaio na gestão de eventos e, pelo outro, na gestão de periódico, impele ao compromisso de construção de algumas páginas sobre as anomalias nesta dimensão. Em virtude de estarmos chegando ao fim do espaço desta oportunidade, apenas duas reflexões serão abordadas. No cenário dos eventos científicos de área de gestão, a deformação mais relevante - cuja solução vem sendo buscada por diversos esforços coletivos no último ano - reside no fato de os eventos terem passado a constituir o principal polo atrator de junk papers e trabalhos oportunistas. Os deadlines funcionam como imperativos que mobilizam a produção de artigos, independente de serem ou não resultados de pesquisa relevante, ou, por vezes, de existir de fato a referida pesquisa. É nesta esfera que a inversão da direcionalidade e da sequência lógica entre investigação-relatório da investigação começa a ser distorcida. Quantos de nós ainda conseguimos escapar a esta anomalia, lembrar do significado pré-produtivista de um evento, e não usar a ameaça do deadline para abortar pesquisas próprias e de alunos? A nossa atitude individual é necessária e anterior a qualquer tentativa de aprimoramento de sistema de avaliação de trabalhos e da qualidade dos eventos.

A análise do papel dos periódicos, mesmo em uma abordagem genérica, exigiria uma reflexão mais completa. Trata-se agora apenas de não deixá-los de fora do ciclo produtivista aqui esboçado, como veículo privilegiado para o escoamento de junk papers. Aqui nos solidarizamos com os editores, avaliadores e funcionários de periódicos que fogem deste perfil e enfrentam, diariamente, a angústia e a indignação diante das anomalias nos papers, autorias, coautorias e outros problemas aqui analisados.

\section{Consequências das anomalias na saúde do professor-pesquisador}

Uma das principais consequências da perversidade do ciclo anômalo analisado reside no fato de que o professor-pesquisador, por sua "própria vontade", a fim de atingir as metas estabelecidas, aumenta em muitas horas seu trabalho semanal. É urgente pararmos para refletir sobre os efeitos em nossa vida pessoal gerados pelo excesso de trabalho. Os riscos na saúde do professor-pesquisador vêm sendo cada vez mais constatados por pesquisadores da área da saúde. Santana (2011) comprovou o que já desconfiávamos, nos últimos anos, docentes de pós-graduação apresentaram aumento nos pedidos de licenças médicas, principalmente por sintomas ou sequelas de doenças cardiovasculares. E o pior, os professores que apresentam maior produção científica são os que apresentam a maior incidência de doenças cardiovasculares e intervenções cardíacas. Machado e Bianchetti (2011) denunciaram a carga horária de três turnos durante seis ou sete dias semanais de professores e descrevem uma longa lista de sintomas identificados em seu estudo nas pós-graduações, que incluem: sintomas psicopatológicos, como depressão e irritabilidade; sintomas psicossomáticos, como 
hipertensão arterial, ataques de asma, úlceras estomacais, enxaquecas e perda de equilíbrio; e sintomas comportamentais, como reações agressivas, transtornos alimentares, aumento de consumo de álcool e tabaco, disfunção sexual e isolamento. Interrogamo-nos se o ethos do individualismo que nos professores se sobressalta é tão forte a ponto de ignorar esse comportamento suicida.

É inquestionável a nossa obediência cega ao sistema, pois são professores que demitem o colega ancião que reduziu seu nível de produção e substituem-no por um colega mais produtivo. São professores que acatam as diretrizes superiores e induzem colegas a trabalharem 60 horas por semana cobrindo quatro funções: professor, pesquisador, orientador e burocrata. No entanto, o grande perdedor nesse sistema é o próprio professor, que também se cansa, adoece e morre na missão masoquista de preservar suas práticas anômalas.

\section{Consequências na formação da nova geração: a perpetuação assegurada pelo sistema}

A outra grande consequência das anomalias aqui esboçadas e que exige reflexão profunda de todos nós é a (de)formação que estamos produzindo na nova geração de pesquisadores. O direcionamento dos professores com melhor formação à pesquisa e o seu corolário, que é o abandono de salas de aula, gera egressos menos preparados. Tais egressos são os aspirantes a pares que recebemos nos programas de pós-graduação. Além de o ensino ser preterido em prol da pesquisa, o que prejudica a sua formação, o pós-graduando sofre dois tipos de pressão muito daninhas: terminar o curso "no prazo" e produzir durante o curso. Exige-se a publicação de artigos por quem ainda não teve a oportunidade de absorver conteúdos. É prática de muitos programas de pós-graduação exigir um artigo por disciplina cursada, mesmo das disciplinas básicas. Se o aluno é brilhante, a pressão é ainda maior, ou seja, em vez de usar seu potencial para formá-lo de maneira mais sólida, a opção é por explorá-lo. E, se o aluno deseja fazer uma pesquisa mais detalhada, coletar mais dados em campo, ou complementar seus estudos em estágios de pesquisa em outras universidades, a resposta é o alerta do prazo. A qualidade aqui também é negligenciada em prol do indicador.

No que tange à formação, o sistema se mostra insustentável na medida em que sacrifica a produção científica consistente do futuro para poder extrair um melhor resultado dos aspirantes atuais. Pesquisadores formados sob a lógica obsessiva da quantidade são quase sempre malformados, limitados e superficiais, pois foram desprovidos da chance de conhecer o verdadeiro significado de universidade, pesquisa, construção do conhecimento, docência e orientação. Ao seguir o exemplo de seus mestres, as novas gerações estão aprendendo que pesquisa é a única atividade acadêmica que dá status, dinheiro e realização pessoal e, portanto, as demais esferas da função social da universidade podem ser negligenciadas. Não se formam mais professores, educadores, apenas pesquisadores e produtores de papers. Porém há os que escapam à regra. Esperamos que a indignação, a capacidade crítica e de transformação inerente aos jovens seja capaz de frear e reverter o modelo que receberam.

\section{Uma palavra final: accountability}

A sociedade é uma das grandes perdedoras do produtivismo que vivenciamos. Accountability parece estar esquecida no atual meio acadêmico. Órgãos de fomento à pesquisa, agências governamentais e fundações de todo tipo não têm o hábito de verificar o fruto do investimento feito em pesquisa. Prestações de contas de natureza contábil visando evitar o mau uso dos recursos são o que se observa. Por fim, a sociedade recebe, como retorno do seu investimento, profissionais limitados e desenvolvimento científico muito aquém das suas necessidades. E isso é tolerado em parte porque o produtivismo é conveniente a quem se adapta ao jogo pela competência. Há inúmeros pesquisadores que conseguem conciliar de forma ética a produção científica de qualidade com a orientação de alunos, a docência, e ao acúmulo de atividade burocrática na universidade. Mas também há os que encontram alguma "onda" para surfar como free riders. Do segundo grupo não esperamos qualquer interesse por mudanças, mas do primeiro acreditamos em uma possibilidade de sensibilização. E dos prejudicados esperamos o fim da passividade. 


\section{Referências}

ALCADIPANI, R. Resistir ao produtivismo: uma ode à perturbação Acadêmica. Cad. EBAPE.BR, v.9, n.4, p. 1741178, 2011.

BETTIS, R. The Search for Asterisks: Compromised Statistical Tests and Flawed Theories Strategic Management Journal, v.3, n.1, p.108-113, 2012.

BIANCHETTI, L.; SGUISSARDI, V. (Orgs.). Dilemas da pós-graduação: gestão e avaliação. Campinas, SP: Autores Associados, 2009.

.; MACHADO, A. M. N. Trabalho docente no stricto sensu: publicar ou morrer? In: FIDALGO, F.; OLIVEIRA, M. A. M.; FIDALGO, N. L. R. (Orgs.). A intensificação do trabalho docente - tecnologias e produtividade. Campinas, SP: Papirus, p. 49-90, 2009.

DEMO, P. Forças e franquezas do positivismo. In: ENCONTRO NACIONAL DA ANPAD, 34, Rio de Janeiro. Anais... Rio de Janeiro: EnANPAD, 2011. (Conferência proferida na Divisão EPQ).

DUARTE JR. J. F. The rotten papers (ou adiós que yo me voy). In: DUARTE JR. J.F. A montanha e o videogame. Escritos sobre educação. Campinas: Papirus, 2010.

DUFOUR, D. R. On achève bien les hommes: de quelques concéquences atuelles et futures de la mort de Dieu. Paris: Éditions Denoël, 2005.

FARIA, A. Repensando produtivismo em gestão no (e a partir do) Brasil. Cad. EBAPE.BR, v.9, n.4, p.1164-1173, 2011.

FREITAS, M. E. O Pesquisador hoje: entre o artesanato intelectual e a produção em série. Cad. EBAPE.BR, v.9, n.4, p.1158-1163, 2011.

GODOI, C. K.; COELHO, A. L. A. L. Análise Sociológica do Discurso: Aproximação dos Elementos Epistemológicos, Metodológicos e Técnicos ao Campo Organizacional. In: ENCONTRO NACIONAL DA ANPAD, 34, Rio de Janeiro. Anais... Rio de Janeiro: EnANPAD, 2011.

HONIG, B.; BEDI, A. The Fox in the Hen House: A Critical Examination of Plagiarism Among Members of the Academy of Management. Academy of Management Learning \& Education, v.11, n.1, p. 101-123, 2012.

LATOUR, B. Jamais fomos modernos: ensaio de antropologia simétrica. Rio de Janeiro: Editora 34, 1994.

Ciência em ação: como seguir cientistas e engenheiros sociedade afora. São Paulo: UNESP, 2000.

MACHADO, A. M. N.; BIANCHETTI, L. (Des)fetichização do produtivismo acadêmico: desafios para o trabalhadorpesquisador. RAE, v.51, n.3, p. 244-254, 2011.

MATTOS, P.L.C. Nós e os índices: a propósito da pressão institucional por publicação. RAE, v.48, n.2, p.144-149, 2008.

PERELMAN, C. O império retórico. Porto: ASA, 1993.

ROSA, A. R. Nós e os índices - um outro olhar sobre a pressão institucional por publicação. Revista de Administração de Empresas, v. 48, n. 4, p. 108-114, out/dez, 2008.

SANTANA, O. A. Docentes de pós-graduação: grupo de risco de doenças cardiovasculares. Acta Scientiarum. Education, v.33, n.2, p. 219-226, 2011. 
SGUISSARDI, V. Produtivismo acadêmico. In: OLIVEIRA, D. A.; DUARTE, A. M. C.; VIEIRA, L. M. F. (Orgs.). Dicionário de Trabalho, Profissão e Condição Docente. Belo Horizonte, MG: Faculdade de Educação/UFMG, 2010a.

Mercantilização e intensificação do trabalho docente - traços marcantes da expansão universitária brasileira hoje. In: LÓPEZ SEGRERA, F.; RIVAROLA, D. M. (Orgs.). La Universidad ante los desafios del siglo XX. I.Assunción: Ediciones y Arte S. A., p. 295-317, 2010 b.

.; SILVA JÚNIOR, J. R. Trabalho intensificado nas federais - pós-graduação e produtivismo acadêmico. São Paulo: Xamã, 2009.

XAVIER, W. G.; GODOI, C. K. Panopticon Acadêmico. Revista Gestão e Planejamento, v.11, n.1, p.91-103, 2010.

WATERS, L. Inimigos da esperança - publicar, perecer e o eclipse da erudição. São Paulo: Editora UNESP, 2006. 